\title{
Neuromodulation for treatment-refractory major depressive disorder
}

\author{
Nir Lipsman MD, Tejas Sankar MD, Jonathan Downar MD PhD, Sidney H. Kennedy MD, \\ Andres M. Lozano MD PhD, Peter Giacobbe MD MSc
}

$\mathrm{M}$ ajor depressive disorder is among the most prevalent psychiatric disorders and is a leading cause of morbidity and lost productivity. ${ }^{1}$ The 1 -year prevalence of major depressive disorder in the Canadian population is $3.2 \%-4.6 \% .^{2} \mathrm{~A}$ large, multisite prospective trial showed that only $28 \%$ of patients experience remission following monotherapy with a serotonin reuptake inhibitor. ${ }^{3}$ Further, remission rates following antidepressant use decrease with each successive treatment failure, such that after 12 months of follow-up and up to 4 attempts at symptom control with different medications, only $60 \%$ of patients experience remission. ${ }^{4,5}$ The remaining patients can be classified as having treatment-refractory depression.

The failure of monoamine-modulating medications to successfully treat a significant percentage of cases of major depressive disorder challenges the traditional conception of this condition as a monoamine deficiency state. Accordingly, and in light of neurocircuitry models of the brain (Appendix 1, available at www .cmaj.ca/lookup/suppl/doi:10.1503/cmaj.121317/ -/DC1) and advances in technology allowing various means of modulating activity in key structures of the brain, interest in the therapeutic potential of neuromodulation for difficult-to-treat mood disorders has increased in recent years. In this review, we outline the mechanisms, safety and clinical evidence for neuromodulation in treatment-refractory major depression. The quality of evidence for the different neuromodulation strategies varies substantially, ranging from small, open-label case series to blinded, randomized controlled trials and meta-analyses (Box 1).

\section{What are the neuromodulation options for major depression?}

Neuromodulation is either noninvasive or invasive, based on the extent to which the technology interacts directly with the brain (Figure 1). Noninvasive options include electroconvulsive therapy, transcranial magnetic stimulation and trans - cranial direct current stimulation. ${ }^{6}$ Invasive options include vagal nerve stimulation ${ }^{7}$ and deep brain stimulation. Here we focus on the 3 modalities for which the most evidence is currently available: electroconvulsive therapy, transcranial magnetic stimulation and deep brain stimulation.

\section{Electroconvulsive therapy}

Electroconvulsive therapy is the oldest neuromodulatory modality still used to treat major depressive disorder. It arguably remains the gold-standard to which other antidepressant treatments are compared, yet it is underused. ${ }^{8}$ Electroconvulsive therapy involves the administration of an electrical current to the brain via the scalp to induce a seizure while the patient is in a state of general anesthesia. Although its mechanisms are unknown, ${ }^{9}$ the superiority of real electroconvulsive therapy over sham electroconvulsive therapy (anesthesia, with or without a subconvulsive dose of electrical current) suggests that the induction of the seizure plays a role in the antidepressant effects of this treatment. ${ }^{10,11}$

Meta-analyses comparing electroconvulsive therapy to antidepressant medication (Table 1) have found that electroconvulsive therapy is superior to medication in reducing depressive symptoms (effect size $0.80,95 \%$ confidence interval [CI] $0.29-1.29)^{10}$ and in achieving an antidepressant response, defined as a $50 \%$ or greater reduction in patients' scores on the Hamilton Rating scale for Depression compared with baseline (odds ratio [OR] 3.72, 95\% CI 2.60-5.32)..$^{11}$ Traditionally, it has been thought that the melan-
Competing interests: See end of article.

This article has been peer reviewed.

Correspondence to: Peter Giacobbe, peter.giacobbe@uhn.on.ca

CMAJ 2014. DOI:10.1503 /cmaj.121317

\section{KEY POINTS}

- Major depressive disorder is often refractory to standard pharmacologic treatment but may respond well to neuromodulation.

- Transcranial magnetic stimulation is least invasive but is less effective than electroconvulsive therapy or deep brain stimulation for treatment of major depression.

- The acceptability and tolerability of electroconvulsive therapy is hampered by adverse effects on episodic memory and other forms of cognition.

- Neuromodulation can lead to major long-term improvements in depression ratings and quality of life. 
cholic subtype of major depressive disorder was the most responsive to electroconvulsive therapy, although recent studies have suggested that electroconvulsive therapy can produce an antidepressant response across multiple subtypes of major depressive episodes. ${ }^{17-19}$ Data from the multicentre study by the Consortium for Research in Electro-

\section{Box 1: Evidence used in this review}

We searched PubMed for articles about neuromodulation in major depression. We used the following search terms alone or in combination: "electroconvulsive therapy," "transcranial magnetic stimulation," "deep brain stimulation," "vagal nerve stimulation," "direct current stimulation," "major depression" and "treatment resistant depression;" we also searched using the acronyms "DBS," "ECT" and "TMS." We did not limit our searches by date. There were no meta-analyses of deep brain stimulation in depression, but we found 21 meta-analyses on electroconvulsive therapy and 17 on transcranial magnetic stimulation. We found no published randomized controlled trials of deep brain stimulation for the treatment of depression. We identified 134 articles on transcranial magnetic stimulation for depression, as well as 230 articles on electroconvulsive therapy. All results were manually searched. We included only those that were relevant and enhanced our discussion and those with clearly defined patient populations and outcome measures. convulsive Therapy suggest that the median number of electroconvulsive therapy treatments required to produce an antidepressant response is 3 , the number for resolution of suicidal thoughts is 4 , and the number for remission is $7 .{ }^{14}$ Given that electroconvulsive therapy is typically administered 2 or 3 times per week during an acute course, achieving a clinically significant response in 1-3 weeks with electroconvulsive therapy compares favourably with the 4-6 weeks typically required with antidepressant medications.

Routine use of general anesthesia, muscle relaxants, continuous oxygenation, vital sign monitoring and brief electrical stimuli have minimized the risks associated with electroconvulsive therapy. The mortality rate has been estimated to be less than 1 death per 73440 treatments. ${ }^{20}$ The most common adverse effects (myalgia [1 in 5 patients], headache [1 in 3 patients]) are transient, lasting minutes to hours, and can be treated with analgesics. ${ }^{21}$ Electroconvulsive therapy is associated with immediate posttreatment disorientation

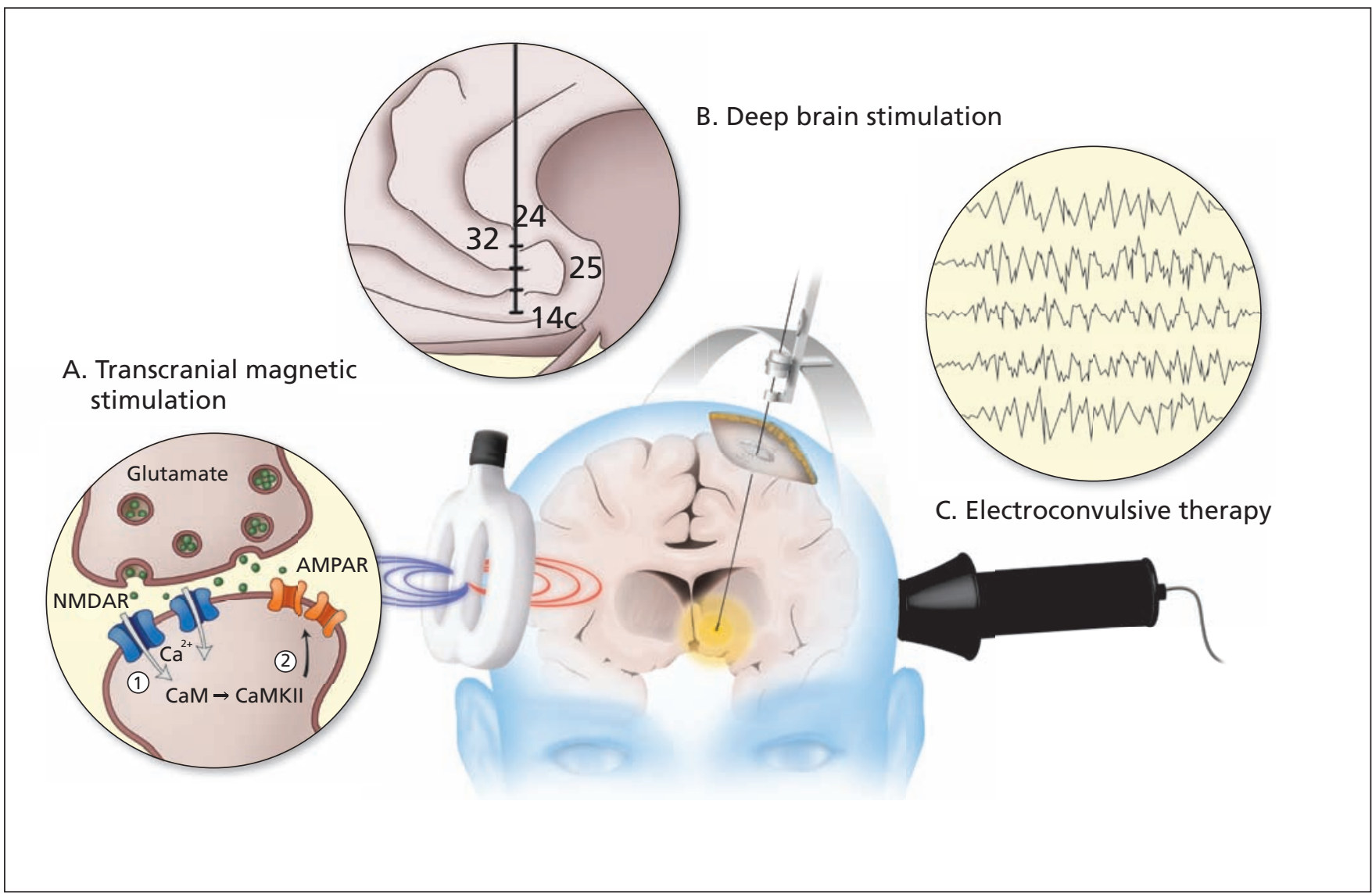

Figure 1: (A) Transcranial magnetic stimulation is thought to produce durable changes in synaptic strength via the NMDA-receptordependent mechanisms of long-term potentiation and long-term depression. Simultaneous stimulation of presynaptic and postsynaptic neurons strengthens or weakens the synaptic connection, depending on the frequency and pattern of stimulation. When applied to areas of prefrontal cortex that are hypoactive in depression, repetitive transcranial magnetic stimulation gradually increases their activity, thereby relieving the illness. (B) With deep brain stimulation, electrodes are inserted under stereotactic guidance into regions of the brain believed to drive maladaptive thoughts and behaviours. Constant electricity, provided by an implanted pulse generator, disrupts neural activity both at local sites (i.e., at the target) and at remote, yet connected, structures, comprising a "mood circuit." (C) Electroconvulsive therapy induces ictal activity, as shown by the electroencephalographic recording. 
and retrograde amnesia. Although these effects are generally short lived, a 6-month longitudinal follow-up study found that retrograde amnesia persisted in about 1 in 8 patients $(12.4 \%){ }^{22}$ The amnestic effects of electroconvulsive therapy are greater for recent events (i.e., within 3 mo of first treatment) than for remote events (i.e., greater than $3 \mathrm{yr}){ }^{23}$ Factors associated with greater $\operatorname{cog}$ nitive impairment following electroconvulsive therapy include pre-existing cognitive impairment, older age and the use of bilateral electroconvulsive therapy. ${ }^{24}$ There are no absolute contraindications to electroconvulsive therapy, and it can be used safely during pregnancy. ${ }^{25}$

\section{Repetitive transcranial magnetic stimulation}

Repetitive transcranial magnetic stimulation uses powerful ( $>2$ Tesla), focused magnetic field pulses to noninvasively stimulate cortical neurons by use of an external electromagnetic coil placed against the patient's scalp. Unlike electroconvulsive therapy, repetitive transcranial magnetic stimulation does not require the administration of anesthesia, and it does not aim to produce a seizure for its therapeutic effects. Trains of repeated stimulation can produce long-lasting changes in neural excitability. The frequency of stimulation determines the effects of transcranial magnetic stimulation. Low-frequency $(<5 \mathrm{~Hz})$ stimulation inhibits neuronal firing, and high-frequency $(>5 \mathrm{~Hz}) \mathrm{stim}-$ ulation increases neuronal firing rates. ${ }^{26}$

Transcranial magnetic stimulation typically involves 10-30 treatment sessions of 15-45 minutes duration, administered once daily, 5 days a week on an outpatient basis. High-frequency stimulation to the dorsolateral prefrontal cortex is the typical protocol for patients with major depressive disorder, based on neuroimaging evidence that this location in the brain is underactive in people with major depression. ${ }^{27}$

Transcranial magnetic stimulation has been shown to be consistently more effective than sham treatment for major depressive disorder across several meta-analyses and large randomized controlled trials (Table 2). In a large metaanalysis involving 24 studies and 1092 patients, active transcranial magnetic stimulation, compared with sham stimulation, was associated with higher pooled rates for response $(25 \% \mathrm{v}$. $9 \%)$ and remission $(17 \%$ v. $6 \%)$; this translates to a number needed to treat of 7 for remission

Table 1: Studies examining the use of electroconvulsive therapy for the treatment of major depressive disorder

\begin{tabular}{|c|c|c|c|}
\hline Study & Study type & $\begin{array}{l}\text { No. of patients; } \\
\text { condition }\end{array}$ & Outcome \\
\hline Sackeim et al. ${ }^{12}$ & $\begin{array}{l}\text { Multicentre RCT, sham } \\
\text { control }\end{array}$ & 290 patients; MDD & $\begin{array}{l}\text { - Decreased 6-mo relapse rates following ECT with } \\
\text { combination of nortriptyline and lithium }(39 \%) \mathrm{v} \text {. } \\
\text { nortriptyline alone }(60 \%) \text { or placebo }(84 \%)\end{array}$ \\
\hline $\begin{array}{l}\text { UK ECT Review } \\
\text { Group }^{10}\end{array}$ & Meta-analysis & $\begin{array}{l}22 \text { trials involving } \\
1408 \text { patients; MDD }\end{array}$ & $\begin{array}{l}\text { - Real ECT was more effective than sham ECT (difference in } \\
\text { HRSD }=9.7,95 \% \mathrm{Cl} 5.7-13.5 \text { ) } \\
\text { - } \mathrm{ECT} \text { was more effective than pharmacotherapy (difference } \\
\text { in HRSD }=5.2,95 \% \mathrm{Cl} 1.4-8.9 \text { ) } \\
\text { - Bilateral ECT was more effective than unipolar ECT } \\
\text { (difference in HRSD }=3.6,95 \% \mathrm{Cl} 2.2-5.2 \text { ) }\end{array}$ \\
\hline Pagnin et al. ${ }^{11}$ & Meta-analysis & $\begin{array}{l}13 \text { RCTs involving } 892 \\
\text { patients; MDD }\end{array}$ & $\begin{array}{l}\text { - Antidepressant response was more likely with real ECT } \\
\text { than with sham ECT (OR } 4.77,95 \% \mathrm{Cl} 2.39-9.49) \\
\text { - Antidepressant response was more likely with ECT than } \\
\text { with medication (OR } 3.72,95 \% \mathrm{Cl} 2.60-5.32 \text { ) }\end{array}$ \\
\hline Husain et al. ${ }^{13}$ & $\begin{array}{l}\text { Multicentre, } \\
\text { prospective, open-label }\end{array}$ & 253 patients; MDD & - Median time to response: $3 \mathrm{ECT}$ treatments \\
\hline Kellner et al. ${ }^{14}$ & $\begin{array}{l}\text { Multicentre, } \\
\text { prospective, open-label }\end{array}$ & $\begin{array}{l}131 \text { patients; MDD } \\
\text { and expressed suicidal } \\
\text { ideation or acts }\end{array}$ & - Median time to relief of suicidal ideation: $4 \mathrm{ECT}$ treatments \\
\hline Kellner et al. ${ }^{15}$ & $\begin{array}{l}\text { Multicentre, parallel- } \\
\text { design RCT }\end{array}$ & $\begin{array}{l}201 \text { patients; MDD } \\
\text { successfully treated } \\
\text { with ECT }\end{array}$ & $\begin{array}{l}\text { Continuation ECT was equally effective in preventing } \\
\text { relapse (6-mo relapse rate } 37.1 \%) \text { as was combination of } \\
\text { nortriptyline and lithium (6-mo relapse rate } 31.6 \%)\end{array}$ \\
\hline Kellner et al. ${ }^{16}$ & $\begin{array}{l}\text { Multicentre, double- } \\
\text { blind RCT }\end{array}$ & $\begin{array}{l}230 \text { patients; MDD or } \\
\text { bipolar disorder }\end{array}$ & $\begin{array}{l}\text { Equivalent remission rates were seen with bitemporal } \\
(64 \%, 95 \% \mathrm{Cl} 53 \%-75 \%) \text {, bifrontal }(61 \%, 95 \% \mathrm{Cl} 50 \%- \\
71 \%) \text { and high-dose right unilateral ECT }(55 \%, 95 \% \mathrm{Cl} \\
43 \%-66 \%)\end{array}$ \\
\hline
\end{tabular}


and 6 for antidepressant response..$^{28}$ Recent openlabel and randomized controlled studies using newer techniques, such as stronger dosing ${ }^{34}$ and longer treatment courses, ${ }^{35}$ have consistently achieved remission rates of $30 \%-35 \%$ and response rates of $40 \%-55 \% .^{33}$

Randomized controlled trials have found that electroconvulsive therapy is superior to transcranial magnetic stimulation in achieving remission $(59.1 \% \text { v. } 16.7 \%)^{36}$ and reducing suicidal thoughts (mean decrease 2.0 v. 0.5 points on the suicide item of the Hamilton Rating scale for Depression) ${ }^{37}$ in short-term studies. Safety, tolerability and noninvasiveness are the major advantages of transcranial magnetic stimulation over electroconvulsive therapy. Transcranial magnetic stimulation does not require general anesthesia or neuromuscular blockade, and patients remain awake throughout treatment. Most studies have found no immediate or prolonged negative effects of transcranial magnetic stimulation on cognition. ${ }^{38}$ A study involving 30 patients with major depressive disorder found that, one week after finishing the course of treatment, cognitive performance remained constant or improved (v. pretreatment) among patients who received transcranial magnetic stimulation to the left dorsolateral prefrontal cortex, while deficits in anterograde memory were observed among patients who underwent right unilateral electroconvulsive therapy. ${ }^{39}$

Transcranial magnetic stimulation may produce transient headache or local pain in $30 \%$ $40 \%$ of patients. ${ }^{40}$ These effects diminish within a few days after treatment and typically respond to over-the-counter analgesics. More serious adverse effects include the emergence of hypomania or suicidal behaviour in less than $1 \%$ of patients. ${ }^{41}$ Very rarely ( $<0.1 \%$ of patients), high-frequency stimulation may induce seizure. There are no known maternal or fetal risks associated with transcranial magnetic stimulation in pregnancy.

\section{Deep brain stimulation}

Deep brain stimulation is the treatment of pathological brain states by the chronic, reversible use of direct electrical current, applied focally to neural elements; this treatment aims to alter their function in isolation or within larger networks. ${ }^{42}$ Deep brain stimulation is a well-established therapy for Parkinson disease, essential tremor and dystonia. The efficacy and safety of deep brain stimulation in treating movement disorders combined with its advantages over traditional ablative neurosurgical procedures (e.g., reversibility, ability to modify stimulation parameters) have spurred its recent application to psychiatric disorders, including major depressive disorder. ${ }^{43}$ Deep brain stimulation is performed through neurosurgically implanted intracranial electrodes connected to a programmable pulse generator in the patient's chest wall; this therapy is the most invasive of all currently available neuromodulation approaches. ${ }^{43}$ Once implanted, stimulation is always on and typically continues indefinitely, with periodic adjustment of stimulation parameters to maintain therapeutic benefit.

The precise mechanisms by which deep brain stimulation exerts its effects are still debated. The early theory that deep brain stimulation simply creates a reversible inhibitory lesion has been

Table 2: Transcranial magnetic stimulation studies

\begin{tabular}{|c|c|c|c|}
\hline Study & Study type & $\begin{array}{l}\text { No. of patients; } \\
\text { condition }\end{array}$ & Outcome \\
\hline Lam et al. ${ }^{28}$ & Meta-analysis & $\begin{array}{l}24 \text { RCTs involving } 1092 \\
\text { patients; MDD or } \\
\text { bipolar disorder }\end{array}$ & $\begin{array}{l}\text { - Pooled } 25 \% \text { response (v. } 9 \% \text { with sham) and } 17 \% \\
\text { remission (v. } 6 \% \text { with sham) with } 1-6 \text { weeks }(5-30 \\
\text { sessions) of active rTMS of the right, left or bilateral DLPFC }\end{array}$ \\
\hline O'Reardon et al..$^{29}$ & $\begin{array}{l}\text { Multicentre RCT, } \\
\text { sham control }\end{array}$ & 301 patients; MDD & $\begin{array}{l}\text { - } 25 \% \text { response (v. } 13.7 \% \text { with sham) and } 16 \% \text { remission } \\
\text { (v. } 8.9 \% \text { with sham) on HRSD-17 with } 6 \text { weeks ( } 30 \text { sessions) } \\
\text { of active rTMS of the left DLPFC }\end{array}$ \\
\hline George et al. ${ }^{30}$ & $\begin{array}{l}\text { Multicentre RCT, } \\
\text { sham control }\end{array}$ & 190 patients; MDD & $\begin{array}{l}\text { - } 15 \% \text { response (v. } 5.0 \% \text { with sham) and } 14 \% \text { remission (v. 5.1\% } \\
\text { with sham) on HRSD-17 with variable 3-6 weeks (15-30 } \\
\text { sessions) active rTMS of the left DLPFC }\end{array}$ \\
\hline Fitzgerald et al. ${ }^{31}$ & $\begin{array}{l}\text { Multicentre } \\
\text { open-label RCT }\end{array}$ & $\begin{array}{l}219 \text { patients; MDD, } \\
\text { bipolar I/II }\end{array}$ & $\begin{array}{l}\text { - } 53 \% \text { response and } 32 \% \text { remission on HRSD- } 17 \text { with } 4 \text { weeks } \\
\text { ( } 20 \text { sessions) active rTMS of the left, right or bilateral DLPFC, } \\
\text { on HRSD-17; no significant differences across target sites }\end{array}$ \\
\hline McDonald et al..$^{32}$ & $\begin{array}{l}\text { Multicentre RCT, } \\
\text { sham control }\end{array}$ & 141 patients; MDD & $\begin{array}{l}\text { - } 41 \% \text { response and } 31 \% \text { remission on HRSD- } 24 \text { with variable } \\
6-12 \text { weeks ( } 30-60 \text { sessions) active rTMS of left DLPFC }\end{array}$ \\
\hline Galletly et al. ${ }^{33}$ & $\begin{array}{l}\text { Multicentre } \\
\text { open-label RCT }\end{array}$ & $\begin{array}{l}77 \text { patients; MDD, } \\
\text { bipolar disorder I//I }\end{array}$ & $\begin{array}{l}\text { - } 43 \% \text { response and } 33 \% \text { remission on HRSD- } 21 \text { with } 4-6 \text { weeks } \\
\text { (18-20 sessions) active rTMS of left and right DLPFC }\end{array}$ \\
\hline
\end{tabular}


supplanted by data suggesting that it produces both immediate and long-term, target-specific effects on neuronal firing rates and patterns. ${ }^{44}$ In major depressive disorder, deep brain stimulation has been used to target nodes within dysregulated mood circuits that perpetuate the depressed state. The most commonly targeted area has been the subgenual cingulate cortex, although the ventral caudate/striatum, nucleus accumbens and inferior thalamic peduncle have also been investigated ${ }^{45-48}$ (Appendix 2, available at www.cmaj.ca/lookup /suppl/doi:10.1503/cmaj.121317/-/DC1).

Two prospective, open-label trials of deep brain stimulation of the subgenual cingulate cortex ${ }^{49,50}$ have shown its efficacy and safety. A Canadian trial performed at 3 centres reported a 6-month response rate of $48 \%$, but a somewhat more disappointing 12-month response rate of 29\%. ${ }^{49}$ Another open-label trial that included patients with major depressive disorder or bipolar disorder found a $58 \%$ remission rate and a $92 \%$ response rate at 2 years. ${ }^{50}$ This trial included a 4 -week single-blind sham lead-in phase to control for placebo response; the authors report that there was a modest stimulation effect of the sham therapy. In both studies, deep brain stimulation was well-tolerated, with no manic or hypomanic episodes, and no suicides were reported. As an invasive neurosurgical procedure, deep brain stimulation carries a small risk of serious complications (e.g., intracranial hemorrhage) and other perioperative risks (e.g., wound infection, anesthetic complications). Larger multicentre trials with longer sham-stimulation periods and true double-blinding are pending.

\section{Which patients should be referred for neuromodulation?}

Box 2 presents a fictional case in which the results of this review are applied in clinical practice. Recent Canadian guidelines about the use of neuromodulation for major depressive disorder have been published (Table 3). ${ }^{51}$ There are currently no Canadian studies examining the cost-effectiveness of neuromodulation strategies for major depressive disorder. Such studies are complex to perform, and they must balance equipment and personnel costs with lost wages and the public health impact of a serious and highly prevalent mental illness.

Currently, electroconvulsive therapy is the most widely used neuromodulation strategy, and it is available in most hospital psychiatric settings.

\section{Box 2: Applying the results of this review in clinical practice (fictional case)}

$Y L$ is a 60 -year-old retired pharmacist and a divorced mother of 3 . She originally received a diagnosis of major depressive disorder when she was 42 years of age. She has received outpatient care for the past 6 years, following a brief stay in hospital for suicidal ideation around the time of separation from her husband. Her condition was initially controlled by a combination of sertraline and bupropion; however, she no longer appears to be responding to previously effective therapies. She underwent cognitive behavioural therapy, but this provided only a modest improvement in her symptoms. Repeated trials of more aggressive pharmacologic regimens (including nortriptyline plus lithium) and subsequently a monoamineoxidase inhibitor (tranylcypromine) were also unsuccessful. She has now lost weight, is growing increasingly despondent and depressed, and her condition is seemingly resistant to pharmacologic treatment.

YL was referred for repetitive transcranial magnetic stimulation and completed a course of 20 sessions of dorsolateral prefrontal cortex stimulation over 4 weeks. Although the procedure was well tolerated and her condition showed some improvement, she did not meet the response ( $>50 \%$ reduction in Hamilton Rating Score for Depression) or remission criteria (Hamilton Rating Score for Depression < 8), 2 months later, she was admitted to hospital after an attempted suicide by medication overdose. She underwent 12 electroconvulsive therapy sessions on an inpatient basis over 6 weeks without appreciable benefit. Reassessment of her diagnosis did not identify major personality pathology, comorbid substance misuse or modifiable life stressors. She was referred to a multidisciplinary team, including a psychiatrist and functional neurosurgeon, for consideration of deep brain stimulation. After discussion of risks and benefits, she elected to proceed with the surgery. Three months later, she underwent successful bilateral implantation of deep brain stimulation electrodes in the subcallosal cingulate, with no adverse effects. By 2 months after implantation, her symptoms were reduced by more than half, and by 6 months she had achieved criteria for remission. Pharmacotherapy was maintained with nortriptyline and lorazepam. Although her condition was in remission, she was able to successfully complete a course of cognitive behavioral therapy; she reported this to be helpful regarding negative thoughts. Two years after implantation, she continues to meet remission criteria and is doing well.

Table 3: Canadian Network for Mood and Anxiety Treatments guidelines for neurostimulation ${ }^{51}$

\begin{tabular}{|c|c|c|c|c|}
\hline Treatment & Overall recommendation & $\begin{array}{c}\text { Acute efficacy } \\
\text { data }\end{array}$ & $\begin{array}{c}\text { Relapse } \\
\text { prevention data }\end{array}$ & $\begin{array}{c}\text { Safety and } \\
\text { tolerability data }\end{array}$ \\
\hline $\begin{array}{l}\text { Electroconvulsive } \\
\text { therapy }\end{array}$ & $\begin{array}{l}\text { First-line therapy for major depressive episode } \\
\text { with psychosis or suicidal ideation; second-line } \\
\text { therapy for treatment-resistant populations }\end{array}$ & Level 1* & Level 1* & Level 2† \\
\hline $\begin{array}{l}\text { Repetitive transcranial } \\
\text { magnetic stimulation }\end{array}$ & Second-line therapy & Level 1* & Level 3‡ & Level 1* \\
\hline Deep brain stimulation & Investigational & Level 3‡ & Level 3‡ & Level 3‡ \\
\hline
\end{tabular}


Guidelines recommend electroconvulsive therapy as a first-line treatment for major depressive disorder in patients with acute suicidal ideation or with psychotic features and as a second-line treatment for major depressive disorder resistant to pharmacotherapy (Table 3). ${ }^{51}$ Electroconvulsive therapy should also be considered for patients who do not have access to transcranial magnetic stimulation or whose condition does not respond to it.

Transcranial magnetic stimulation is available in most academic centres and in a small, but growing, number of community clinics. It may be used either as an add-on treatment to medication or as a stand-alone alternative for patients who decline or do not tolerate medication; it may be a good option for patients whose condition has proven refractory to initial trials of medication.

Deep brain stimulation is reserved for patients who meet the criteria for severe and intractable major depression and whose condition has failed to respond to at least 4 different treatments, including appropriate trials of antidepressant medication, evidence-based psychotherapy and electroconvulsive therapy. ${ }^{52-54}$ Currently, patients who meet these or other similarly rigorous criteria can be referred for assessment to selected centres with a multidisciplinary psychiatric surgery team. In Canada, deep brain stimulation for major depressive disorder has largely been undertaken within clinical trials, but it may be offered as an off-label procedure in select cases.

\section{References}

1. Kessler RC, Berglund P, Demler O, et al. The epidemiology of major depressive disorder: results from the National Comorbidity Survey Replication (NCS-R). JAMA 2003;289:3095-105.

2. Lam RW, Kennedy SH, Grigoriadis S, et al. Canadian Network for Mood and Anxiety Treatments (CANMAT) clinical guidelines for the management of major depressive disorder in adults. III. Pharmacotherapy. J Affect Disord 2009;117(Suppl 1):S26-43.

3. Trivedi MH, Rush AJ, Wisniewski SR, et al. Evaluation of outcomes with citalopram for depression using measurement-based care in STAR*D: implications for clinical practice. Am J Psychiatry 2006;163:28-40.

4. McGrath PJ, Stewart JW, Fava M, et al. Tranylcypromine versus venlafaxine plus mirtazapine following three failed antidepressant medication trials for depression: a STAR*D report. Am J Psychiatry 2006;163:1531-41.

5. Giacobbe P, Mayberg HS, Lozano AM. Treatment resistant depression as a failure of brain homeostatic mechanisms: implications for deep brain stimulation. Exp Neurol 2009;219:44-52

6. Nitsche MA, Boggio PS, Fregni F, et al. Treatment of depression with transcranial direct current stimulation (tDCS): a review. Exp Neurol 2009;219:14-9.

7. Rizvi SJ, Donovan M, Giacobbe P, et al. Neurostimulation therapies for treatment resistant depression: a focus on vagus nerve stimulation and deep brain stimulation. Int Rev Psychiatry 2011; 23:424-36.

8. Rapoport MJ, Mamdani M, Herrmann N. Electroconvulsive therapy in older adults: 13-year trends. Can J Psychiatry 2006;51:616-9.

9. Bolwig TG. How does electroconvulsive therapy work? Theories on its mechanism. Can J Psychiatry 2011;56:13-8.

10. UK ECT Review Group. Efficacy and safety of electroconvulsive therapy in depressive disorders: a systematic review and meta-analysis. Lancet 2003;361:799-808.

11. Pagnin D, de Queiroz V, Pini S, et al. Efficacy of ECT in depression: a meta-analytic review. J ECT 2004;20:13-20.

12. Sackeim HA, Haskett RF, Mulsant BH, et al. Continuation pharmacotherapy in the prevention of relapse following electrocon- vulsive therapy: a randomized controlled trial. JAMA 2001;285: 1299-307.

13. Husain MM, Rush AJ, Fink M, et al. Speed of response and remission in major depressive disorder with acute electroconvulsive therapy (ECT): a Consortium for Research in ECT (CORE) report. J Clin Psychiatry 2004;65:485-91.

14. Kellner CH, Fink M, Knapp R, et al. Relief of expressed suicidal intent by ECT: a consortium for research in ECT study. Am J Psychiatry 2005;162:977-82.

15. Kellner CH, Knapp RG, Petrides G, et al. Continuation electroconvulsive therapy vs pharmacotherapy for relapse prevention in major depression: a multisite study from the Consortium for Research in Electroconvulsive Therapy (CORE). Arch Gen Psychiatry 2006;63:1337-44.

16. Kellner CH, Knapp R, Husain MM, et al. Bifrontal, bitemporal and right unilateral electrode placement in ECT: randomised trial. Br J Psychiatry 2010;196:226-34.

17. Petrides G, Fink M, Husain MM, et al. ECT remission rates in psychotic versus nonpsychotic depressed patients: a report from CORE. J ECT 2001;17:244-53.

18. Husain MM, McClintock SM, Rush AJ, et al. The efficacy of acute electroconvulsive therapy in atypical depression. J Clin Psychiatry 2008;69:406-11.

19. Bailine S, Fink M, Knapp R, et al. Electroconvulsive therapy is equally effective in unipolar and bipolar depression. Acta Psychiatr Scand 2010;121:431-6.

20. Watts BV, Groft A, Bagian JP, et al. An examination of mortality and other adverse events related to electroconvulsive therapy using a national adverse event report system. J ECT 2011;27: 105-8

21. Dinwiddie SH, Huo D, Gottlieb O. The course of myalgia and headache after electroconvulsive therapy. J ECT 2010;26:116-20.

22. Sackeim HA, Prudic J, Fuller R, et al. The cognitive effects of electroconvulsive therapy in community settings. Neuropsychopharmacology 2007;32:244-54.

23. Lisanby SH, Maddox JH, Prudic J, et al. The effects of electroconvulsive therapy on memory of autobiographical and public events. Arch Gen Psychiatry 2000;57:581-90.

24. Moreines JL, McClintock SM, Holtzheimer PE. Neuropsychologic effects of neuromodulation techniques for treatment-resistant depression: a review. Brain Stimul 2011;4:17-27.

25. Yonkers KA, Wisner KL, Stewart DE, et al. The management of depression during pregnancy: a report from the American Psychiatric Association and the American College of Obstetricians and Gynecologists. Gen Hosp Psychiatry 2009;31:403-13.

26. Speer AM, Kimbrell TA, Wassermann EM, et al. Opposite effects of high and low frequency rTMS on regional brain activity in depressed patients. Biol Psychiatry 2000;48:1133-41.

27. Hamilton JP, Etkin A, Furman DJ, et al. Functional neuroimaging of major depressive disorder: a meta-analysis and new integration of base line activation and neural response data. Am J Psychiatry 2012; 169:693-703.

28. Lam RW, Chan P, Wilkins-Ho M, et al. Repetitive transcranial magnetic stimulation for treatment-resistant depression: a systematic review and metaanalysis. Can J Psychiatry 2008;53:621-31.

29. O'Reardon JP, Solvason HB, Janicak PG, et al. Efficacy and safety of transcranial magnetic stimulation in the acute treatment of major depression: a multisite randomized controlled trial. Biol Psychiatry 2007;62:1208-16.

30. George MS, Lisanby SH, Avery D, et al. Daily left prefrontal transcranial magnetic stimulation therapy for major depressive disorder: a sham-controlled randomized trial. Arch Gen Psychiatry 2010;67:507-16.

31. Fitzgerald PB, Hoy K, Gunewardene R, et al. A randomized trial of unilateral and bilateral prefrontal cortex transcranial magnetic stimulation in treatment-resistant major depression. Psychol Med 2011;41:1187-96.

32. McDonald WM, Durkalski V, Ball ER, et al. Improving the antidepressant efficacy of transcranial magnetic stimulation: maximizing the number of stimulations and treatment location in treatment-resistant depression. Depress Anxiety 2011;28:973-80.

33. Galletly C, Gill S, Burton C, et al. A randomized trial comparing repetitive transcranial magnetic stimulation given 3 days/week and 5 days/week for the treatment of major depression: Is efficacy related to the duration of treatment or the number of treatments? Psychol Med 2012;42:981-8.

34. Hadley D, Anderson BS, Borckardt JJ, et al. Safety, tolerability, and effectiveness of high doses of adjunctive daily left prefrontal repetitive transcranial magnetic stimulation for treatment-resistant depression in a clinical setting. J ECT 2011;27:18-25.

35. McDonald WM, Durkalski V, Ball ER, et al. Improving the antidepressant efficacy of transcranial magnetic stimulation: maximizing the number of stimulations and treatment location in treatment-resistant depression. Depress Anxiety 2011;28:973-80. 
36. Eranti S, Mogg A, Pluck G, et al. A randomized, controlled trial with 6-month follow-up of repetitive transcranial magnetic stimulation and electroconvulsive therapy for severe depression. Am J Psychiatry 2007;164:73-81

37. Keshtkar M, Ghanizadeh A, Firoozabadi A. Repetitive transcranial magnetic stimulation versus electroconvulsive therapy for the treatment of major depressive disorder, a randomized controlled clinical trial. J ECT 2011;27:310-4.

38. Moreines JL, McClintock SM, Holtzheimer PE. Neuropsychologic effects of neuromodulation techniques for treatment-resistant depression: a review. Brain Stimul 2011;4:17-27.

39. Schulze-Rauschenbach SC, Harms U, Schlaepfer TE, et al. Distinctive neurocognitive effects of repetitive transcranial magnetic stimulation and electroconvulsive therapy in major depression. Br J Psychiatry 2005;186:410-6.

40. Loo CK, McFarquhar TF, Mitchell PB. A review of the safety of repetitive transcranial magnetic stimulation as a clinical treatment for depression. Int J Neuropsychopharmacol 2008;11:131-47.

41. Rossi S, Hallett M, Rossini PM, et al. Safety, ethical considerations, and application guidelines for the use of transcranial magnetic stimulation in clinical practice and research. Clin Neurophysiol 2009;120:2008-39.

42. Kringelbach ML, Jenkinson N, Owen SL, et al. Translational principles of deep brain stimulation. Nat Rev Neurosci 2007;8:623-35.

43. Holtzheimer PE III, Mayberg HS. Deep brain stimulation for treatment-resistant depression. Am J Psychiatry 2010;167:1437-44.

44. Johnson MD, Miocinovic S, McIntyre CC, et al. Mechanisms and targets of deep brain stimulation in movement disorders. Neurotherapeutics 2008;5:294-308.

45. Bewernick BH, Hurlemann R, Matusch A, et al. Nucleus accumbens deep brain stimulation decreases ratings of depression and anxiety in treatment-resistant depression. Biol Psychiatry 2010; 67:110-6.

46. Jiménez F, Velasco F, Salin-Pascual R, et al. A patient with a resistant major depression disorder treated with deep brain stimulation in the inferior thalamic peduncle. Neurosurgery 2005;57:585-93.

47. Malone DA Jr, Dougherty DD, Rezai AR, et al. Deep brain stimulation of the ventral capsule/ventral striatum for treatmentresistant depression. Biol Psychiatry 2009;65:267-75.

48. Schlaepfer TE, Cohen MX, Frick C, et al. Deep brain stimulation to reward circuitry alleviates anhedonia in refractory major depression. Neuropsychopharmacology 2008;33:368-77.

49. Lozano AM, Giacobbe P, Hamani C, et al. A multicenter pilot study of subcallosal cingulate area deep brain stimulation for treatment-resistant depression. J Neurosurg 2012;116:315-22.

50. Holtzheimer PE, Kelley ME, Gross RE, et al. Subcallosal cingulate deep brain stimulation for treatment-resistant unipolar and bipolar depression. Arch Gen Psychiatry 2012;69:150-8.

51. Kennedy SH, Milev R, Giacobbe P, et al. Canadian Network for Mood and Anxiety Treatments (CANMAT) Clinical guidelines for the management of major depressive disorder in adults. IV. Neurostimulation therapies. J Affect Disord 2009;117(Suppl 1): S44-53.

52. Lozano AM, Mayberg HS, Giacobbe P, et al. Subcallosal cingulate gyrus deep brain stimulation for treatment-resistant depression. Biol Psychiatry 2008;64:461-7.

53. Mayberg HS, Lozano AM, Voon V, et al. Deep brain stimulation for treatment-resistant depression. Neuron 2005;45:651-60.

54. Kennedy SH, Giacobbe P, Rizvi SJ, et al. Deep brain stimulation for treatment-resistant depression: follow-up after 3 to 6 years. Am J Psychiatry 2011;168:502-10.

Competing interests: Jonathan Downar has received a travel stipend from Lundbeck. Sidney Kennedy has received grants from Bristol-Myers Squibb and Clera. He has received grants and personal fees from Lundbeck, Servier and St. Jude Medical, and personal fees from Eli Lilly, Pfizer, Abbott Laboratories, AstraZeneca, Elsevier, Glia Communications, Indegene Lifesystems, Spimaco, Symbiote Medical Communications Inc. and Spirant Communi- cations. Andres Lozano has received personal fees from Functional Neuroscience and is a consultant for Ceregene, Medtronic, Boston Scientific and St. Jude Medical. Peter Giacobbe is a consultant for St. Jude Medical and has received personal fees from Eli Lily Canada, Bristol-Myers Squibb, AstraZeneca and Pfizer. He holds grants from the Michael J. Fox Foundation for Parkinson's Research, National Institutes of Health and the Schizophrenia Society of Ontario. No competing interests declared by Nir Lipsman or Tejas Sankar.

Affiliations: Division of Neurosurgery (Lipsman, Lozano), Toronto Western Hospital, Toronto, Ont.; Division of Neurosurgery (Sankar), University of Alberta, Edmonton, Alta.; and the Department of Psychiatry (Downar, Kennedy, Giacobbe), University Health Network, University of Toronto, Toronto, Ont.

Contributors: Nir Lipsman and Peter Giacobbe conceived the article. All of the authors contributed to writing and revising the manuscript and approved the final version submitted for publication. 